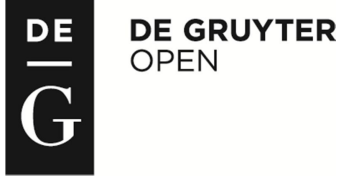

DOI: 10.1515/jolace-2015-0008

\title{
Enhancing student schematic knowledge of culture through literature circles in a foreign language classroom
}

\author{
Alastair Graham-Marr \\ Tokyo University of Science, Japan \\ gmarr@rs.kagu.tus.ac.jp
}

\begin{abstract}
Improving student understanding of a foreign language culture is anything but a peripheral issue in the teaching of a foreign language. This pilot study reports on a second year required English course in a university in Japan that took a Literature Circles approach, where students were asked to read short stories out of class and then discuss these stories in class. Although students reported that they did not gain any special insights into the target language culture presented, they did report that reading fiction as source material for classroom activity helps with the acquisition of a vocabulary set that is more closely associated with lifestyle and culture. The results suggest that further study is warranted. Procedures of this pilot study are described and interpreted in the context of the English education system in Japan.
\end{abstract}

Keywords

literature circles, vocabulary acquisition, intercultural communication, Japan

\section{Introduction}

Communicating effectively in a foreign or second language requires more than just mastery of the linguistic code, intercultural competence also underlies effective foreign language communication. Meaning that the study of a foreign language should not simply be a matter of learning an isolated linguistic code as an object of academic study, it should involve practice in using the language in intercultural contexts, leading to the development of real-world communication skills. Communicative events are rarely out of context, and given that cultural conventions shape how communicative events unfold, such events are rarely culture-free. Knowledge of a linguistic code alone is often insufficient for effective communication.

In Japan, English education has undergone a series of reforms over the past thirty years, to address the constant problem of needing workers who can communicate effectively with the world outside of Japan. The word kokusaika (internationalization) emerged as a popular expression during the 1980s as Japan expanded its economic might, and today, three decades later, the term is still widely used to describe the ongoing need for Japanese working in professional fields to cultivate the necessary skills to participate actively within the international community. The Ministry of Education, Science and Technology (MEXT) has taken many initiatives to promote the development of more communicative English skills. It has encouraged communicative teaching methods, in place of traditional grammartranslation teaching methods, as one such remedy. In 1994 the ministry introduced a new course of study in Japanese high schools, English Oral Communication, in order to foster more communicative speaking abilities. In 2003, MEXT announced the National Action Plan to Cultivate Japanese with English Abilities aimed at improving the communicative English abilities of Japanese high school students. In early 2014, MEXT announced the "full-scale development of new English education in Japan" in order to improve communicative English speaking skills for the 2020 Olympics. 
However, while there is much discussion about educational reform, many obstacles remain which prevent teachers from taking up these initiatives and trying to help students improve their intercultural communication skills. Gorsuch (1998) has identified three obstacles which act to inhibit the development of intercultural communicative English skills in Japanese high schools and these three factors are still very much relevant today: a heavily grammar-oriented curriculum with too much yakudoku, a grammar translation activity where complex English grammatical patterns are rendered into Japanese, the university entrance exam system, which demands that students possess a passive understanding of complex grammatical rules, and finally a lack of teacher training in communicative teaching methods.

High school teachers are constrained by the university entrance exam system in Japan and often feel, quite rightly, that their first responsibility is to help students pass these entrance exams and gain access to an elite education and a chance at a better life. Unsurprisingly, many teachers spend a great deal of the available class time focussing on isolated elements of grammar to help students better answer these exam questions correctly and will often neglect the teaching of English as a tool for intercultural communication.

Students in Japan rarely have opportunities to use English as a tool for giving and getting information, processing information, reporting information, or synthesizing and comparing information; that is, English is rarely used as a tool of academic endeavor. Given the need to both enhance student abilities to use English as a medium of information exchange and also promote intercultural understanding, this study investigates the validity of using a Literature Circles approach as a way to improve communicative skills while introducing a cultural component through the use of target language literature as source material for the class.

With such a clearly defined need, language teachers are being urged to develop curricula that can foster communicative language skills and also intercultural competence. One way to accomplish this is through the use of literature. The Modern Language Association Ad Hoc Committee on Foreign Languages (2007), for example, recommends raising intercultural competence by having students read, comprehend, and analyze narratives in the target language.

One way to teach literature communicatively is through the use of Literature Circles (LC), a type of peer discussion class activity put forward by Harvey Daniels, an American teacher and researcher. First of all, reading has long been recognized as a useful pathway to L2 mastery. As noted by Barrette et al. (2010), literature is one type of target language narrative that exposes students to comprehensible input, facilitating language acquisition. Secondly, reading which is followed up with communicative activities that force students to output language has also been found to be highly effective for both vocabulary development and language acquisition in general. (see for example, Altman, 1997; Coady, 1997; Joe, 1998; Ellis and Xe 1999). Lastly, using literature as source material for classroom discussion exposes students to words, phrases and idioms that are more associated with lifestyle and culture than they might otherwise encounter in a typical EFL/ESL classroom.

\section{Source Material}

The source material chosen for the class was a story, graded and written for intermediate EFL students. The book was written with simplified grammar and a limited vocabulary set, chosen to match the level of the class. The reading material was selected following the advice of Nation (2001), that adequate comprehension can be achieved when students read materials in which $98 \%$ of the running words are known. The book was also chosen because of its format, two short stories, divided into 6 chapters, which made it ideal for use over a 15 class term.

The two stories were both detective stories, and focussing the reading on a single genre can help students develop a better feel for the language, style and literary conventions associated with that genre. Furthermore, there is some research which suggests that having students focus on a single genre rather than a wide variety of genre is advantageous for second language acquisition, as students get multiple exposures to a vocabulary set which is associated with that particular genre (see Krashen, 
2004). Both stories were whodunit mystery stories set in Washington, D.C.. The main character in the stories was a female detective of mixed Chinese- Peruvian heritage working for the Washington D.C. police department.

By focusing on the mystery genre, students were repeatedly exposed to words that they might not encounter in a typical EFL/ESL class. For example, some of the words and expressions that were used repeatedly and associated with the detective story genre included: dust for fingerprints, drugged, wall safe, combination, glance nervously and so on. Other words more associated with lifestyle included: prescription, allergic, allowance, fiancé, prescription, sigh, mumble and so on. The use of these stories gave students exposure to a wider range of words and expressions.

\section{Class Procedure}

Students came to each class having read one chapter from the book as homework, typically 7 pages or 2,000 words. In addition to the reading, students had to check their understanding by doing a series of comprehension check questions. In class, students were put into groups of four to do discussion sessions which were then repeated four or five times to build fluency.

Following the advice of Furr (2004), the Literature Circles (LC) were set up as follows:

\section{The instructor selected materials appropriate to the level of the class.}

Although in L1 educational contexts, most practitioners of LC recommend that students select their own books to read in order to promote interest and raise motivation, in an EFL context having graded texts that are somewhat more easy to read can help students more easily comprehend the story, promoting reading fluency and allowing students to enjoy the text by getting to meaning more effortlessly. To make sure students were reading materials appropriate to their level, the materials were selected by the instructor.

\section{Small temporary groups were arranged at the instructor's discretion.}

In order to better manage the group dynamics of the class and maximize student participation, groups were formed and changed using a random numerical system. Students were not allowed to choose their own groups in an effort to avoid having all the strong students together in one group, or having groups of friends form cliques together. When groups are formed and reformed according to a random numerical system, students get opportunities to interact with a wider variety of people than they might have had they formed groups by themselves.

\section{The whole class read the same material.}

In L1 LC, students read different stories. However, in an EFL context, all students read the same story. This means that all students will be familiar with the basic content of all the spoken interaction during the group discussion and can better understand the discussion, leading to improved fluency.

\section{Students discussed the source material using a predictable and structured format.}

In order for LC to work well, a certain amount of student training is needed. Students need to become familiar with their roles. A structured and predicable format helps students to understand what is expected of them, and what is expected of each role in the discussion.

Within their groups, each student was assigned a role on the day of the class. The roles were as follows:

a. Leader: leads the discussion and asks questions.

b. Summarizer: summarizes the story to date and also the current week's chapter.

c. Detail master: answers questions asked by the leader about details of the story.

d. Vocabulary master: explains the meanings of words using their own words.

5. Students were allowed to use written prepared notes to help with their discussions.

The role of the summarizer demands that students be able to relate the narrative. Allowing students to create story maps, helps the summarizer give a more detailed account of the main story.

\section{The teacher played the role of facilitator, not a group member or an instructor.}


Once groups have been set up and the students understand what is expected of them, the teacher needs to step back and allow the students to take responsibility for the maintenance of group discussion.

\section{Task repetition was crucial for fluency development.}

Discussion sessions typically last five to seven minutes. Bearing in mind the value of task repetition, having students do these sessions multiple times leads to improved performance. Students learn from their mistakes, improve their fluency and also gain confidence with each repetition. Repetition can be facilitated by changing the group membership, so that each group has entirely new members with each cycle. Changing group membership also gives the activity some communicative purpose, as fresh discussions can be had with the new members.

\section{In between cycles, the teacher provided models.}

In between cycles, the teacher gave his own summaries of the story to date, the chapter being done that week, explanations of some vocabulary items and examples of questions and answers to the details of the story as models for the students to emulate should they choose to.

\section{At the end of each story, students did project work to facilitate review.}

As a review project, poster sessions were done by having students present on a specific character from the book in small group poster presentations.

\section{Questions}

The present pilot study investigated student opinion about the LC approach from a number of different perspectives. The following questions were asked:

1. Had students previously experienced an LC approach?

2. Was the experience positive or negative?

3. Did this approach contribute to vocabulary learning?

4. Was LC more effective than traditional methods in helping students learn new words?

5. Was LC more effective than traditional methods in helping students learn how to use their new words?

6. Did LC help students to learn something about North American culture?

7. Did students feel that the use of fictional literature as source material helped foster a better understanding of words associated with lifestyle and culture?

8. Did students feel that learning these sorts of words was valuable.

\section{Method}

\section{Participants}

The participants in the study were 78 second year chemical engineering university students (53 males and 25 females) studying English as a required second year course at a well regarded science university in Tokyo. Most of the students in the class were quite motivated to learn English, seeing English as important for their futures. Although the English proficiency level of the students was not directly measured during the course of this study, given that all students passed a rigorous entrance exam to enter the university, most of the students in the chemical engineering department could be said to be at an intermediate or threshold level (CEFR B1) of English proficiency. There were 78 students registered in the class, however we were only able to use survey data from 62 students due to either incomplete data on the questionnaire or student absences on the day the survey was administered.

\section{Instrumentation}

To investigate these questions an 11 item questionnaire was administered at the end of the course. The questions were asked in Japanese and students were encouraged to make further comments in either English or Japanese. A translation of the questionnaire is included in the appendix. 


\section{Results}

Most students in the study had not previously experienced literature circles, as $82 \%$ of students reported that it was a novel experience for them. In addition, the majority of students felt that the classes were useful, with $75 \%$ of students rating the approach as positive. Students gave a variety of reasons for their positive and negative ratings. The most common reason cited for a positive rating was that students were able to use and think in English. Other reasons given were that students were able to actively participate and participate equally due to the defined speaking roles. Others cited the need to preview before class as contributing to an overall positive experience. The two main reasons given for a negative rating were that there were a few students that didn't properly prepare for the class and that there were some gaps in student motivation, meaning that students who didn't participate actively impeded some of the group discussion.

In terms of learning new vocabulary, literature circles was not felt to be superior, however in terms of learning to use new vocabulary, literature circles was rated as being more effective than traditional methods. When asked to compare literature circles with more traditional approaches in terms of helping students learning to use newly acquired vocabulary, $66 \%$ of students rated LC as being superior, $10 \%$ rated LC as inferior and $24 \%$ rated LC as being equal to other more traditional approaches.

In terms of gaining an understanding of a target language culture, although students reported that they did not gain any significant understanding of the target language culture through the use of LC, they did feel that using fiction as source material is useful for learning words typically associated with lifestyle and culture, with $94 \%$ of students reporting affirmatively that reading fiction is helpful for gaining an understanding of words associated with lifestyle and culture. The results from the questionnaire are reported in Table 1.

\begin{tabular}{|c|c|c|c|}
\hline Questions & Yes & Unsure & No \\
\hline 1. Have you previously experienced literature circles? & 11 & - & 51 \\
\hline 2. Was the experience positive? & 47 & - & 15 \\
\hline 3. Did the approach contribute to vocabulary learning? & 26 & 28 & 8 \\
\hline $\begin{array}{l}\text { 4. Was LC more effective than traditional methods for helping students } \\
\text { learn new words? }\end{array}$ & 14 & 28 & 20 \\
\hline $\begin{array}{l}\text { 5. Was LC more effective than traditional classes in helping students } \\
\text { develop an understanding of how to use words? }\end{array}$ & 41 & 15 & 6 \\
\hline $\begin{array}{l}\text { 6. Did you feel that Whodunit helped you to learn something about } \\
\text { North American culture? }\end{array}$ & 13 & & 49 \\
\hline 7. Does literature, (fiction) help 'cultural' vocabulary acquisition? & 58 & 4 & 0 \\
\hline $\begin{array}{l}\text { 8. Is it useful to learn words that are associated with lifestyle and } \\
\text { culture? }\end{array}$ & 24 & 37 & 1 \\
\hline
\end{tabular}

Table 1: Questionnaire results 


\section{Discussion}

The purpose of this pilot study was to identify aspects of this class procedure that might merit further study with respect to language acquisition and intercultural understanding. Secondly, through this study we could identify aspects of the class procedure in need of further adjustment.

That students did not find a role for LC in promoting a better understanding of the target language culture, possibly suggests that a more overt approach to the teaching of culture was needed. Murphey (1988) has suggested four general approaches to the teaching of cultural content, two implicit approaches, where culture is not taught explicitly but is assumed to come with the language, and two that are more explicit. The LC approach used in this study is an example of the former, suggesting that perhaps more attention could have been focused on culture by adding cultural content as an explicit educational objective rather than leaving it embedded within the source material.

Student opinion on the role of LC in promoting vocabulary acquisition was mixed. However, given that many methods of learning vocabulary have been shown to be effective, the results are not surprising. Vocabulary is learned through repeated exposure and deeper levels of linguistic processing. This can be accomplished in many ways, and is not limited to group in-class discussion. For example, in a study comparing integrated and isolated form-focused instruction, File and Adams (2010) found that isolated form-focused instruction can lead to higher rates of learning than integrated instruction. However, both integrated form-focused instruction and isolated form-focused instruction were superior to incidental exposure alone. As LC uses an integrated approach, student opinion seems to match these research findings.

Student impressions of LC was most positive in its role facilitating a better understanding of how to use newly learned words. Words needs to be met and met again to facilitate retention and they also need to be used and used again to consolidate learning to a point of being able to use newly learned words with confidence. As Schmitt points out, "the overriding principle for maximizing vocabulary learning is to increase the amount of engagement learners have with lexical items," (Schmitt, 2008, p. 329) and with an LC approach, students need to recall and summarize the story in addition to having to define and explicitly discuss vocabulary items, which increases the amount of engagement students have with the lexical items.

Student opinion about LC in its role promoting vocabulary use once again matches research findings which have shown that learners who have had their attention focused on vocabulary items are better able to recall and use those words. Depth of processing or degree of elaboration has long been associated with more effective learning (see Laufer \& Hulstijn, 2001).

Laufer and Hulstijn (2001) have proposed a task-induced involvement model of vocabulary acquisition named the Involvement Load Hypothesis which proposes that words which have been processed with higher involvement loads, defined as being based on the cognitive dimensions of search and evaluation involving noticing and the deliberate allocation of attention to a word's form-meaning relationship, leads to higher levels of retention than words which have been processed with lower involvement loads. With respect to LC, the tasks associated with the role of Vocabulary Master force students to come up with their own definitions and explanations of newly learned words during group discussion. This focuses student attention on form, and forces students to process words with higher levels of involvement.

The use of literature as source material most certainly provides a vehicle for cultural content. However, the results suggest that cultural differences need to be clearly identified and pointed out to students. The teaching of culture implicitly through literature, without activities to raise student awareness of these issues, might not lead to significant gains in intercultural understanding, at least within the confines of a single school term.

The LC approach, however, does seem to be a useful method for improving basic langauge competencies. The approach gives students many opportunities to practice the language, leading to language acquisition and improved fluency. The results from this pilot study suggest that further empirical research verifying this finding is warranted. Pre-tests and post-tests of vocabulary items 
associated with the target language culture would add empirical support for the proposition that the LC approach enhances the acquisition of vocabulary items associated with culture. Furthermore, pre and post testing could also establish to what extent the approach helps students use their newly learned words.

\section{Conclusion}

The goal of this article has been to put forward the LC approach as a way to introduce cultural content into foreign language classrooms, and to identify aspects of this approach in need of empirical verification. The results suggest that concrete pre and post testing of vocabulary items would be a useful next step. The qualitative data elucidated in this study supports previous empirical studies, however more data is needed to verify the validity of this approach in promoting intercultural understanding, language acquisition and fluency development.

The results also suggested that the cultural content found in the source material should be pointed out more explicitly through awareness raising activities. This suggests that some adjustments need to be made to the current class procedures. That being said, if cultural content is to be added to foreign language curricula, literature circles seem like a promising vehicle to deliver that cultural content while helping students to achieve higher levels of fluency and provide students with opportunities for language acquisition. In the context of the educational system in Japan, introducing literature circles into the classroom seems like a good way to meet many of the curriculum goals that have been expressed by MEXT. If Japan is looking to the 2020 Olympics as a way to stimulate further educational reform, literature circles could be one option.

\section{References}

Altman, R. (1997). Oral production of vocabulary: A case study. In Coady, J. \& Huckin, T. (Eds), Second Language Vocabulary Acquisition (pp. 69-97). Cambridge: Cambridge University Press.

Barrette, C., Paesani, K.. \& Vinall, K. (2010). Toward an integrated curriculum: Maximizing the use of target language literature. Foreign Language Annals, 43(2), 216-230

Coady, J. (1997). L2 vocabulary acquisition: a synthesis of the research. In Coady, J. \& Huckin, T. (Eds.), Second Language Vocabulary Acquisition (pp. 273-290). Cambridge: Cambridge University Press.

Ellis, R. \& Xe, H. (1999). The roles of modified input and output in the incidental acquisition of word meanings. Studies in Second Language Acquisition, 21, 285-301.

File, K. A. \& Adams, R. (2010). Should Vocabulary Instruction be integrated or isolated? TESOL Quarterly, $44(2), 222-249$.

Furr, M. (2004). Literature circles for the EFL classroom. Proceedings of the 2003 TESOL Arabia Conference, Dubai, United Arab Emirates: TESOL Arabia.

Gorsuch, G. J. (1998). Yakudoku: EFL instruction in two Japanese high school classrooms: An exploratory study. JALT Journal, 20(1), 6-32.

Krashen, S. (2004). The case for narrow reading. Language Magazine, 3(5), 17-19.

Joe, A. (1998). What effects do text-based tasks promoting generation have on incidental vocabulary acquisition? Applied Linguistics, 19(3), 357-377.

Laufer, B. \& Hulstijn, J. (2001). Incidental vocabulary acquisition in a second language: The construct of task-induced involvement. Applied Linguistics, 22(1), 1-26.

Modern Language Association. (2007). Foreign languages and higher education: New structures for a changed world. Ad Hoc Committee on Foreign Languages. Retrieved from http://www.mla.org/flreport

Murphey, E. (1988). The cultural dimension in foreign language teaching: Four Models. Language, Culture and Curriculum, 1(2), 147-163.

Nation, I. S. P. (2001). Learning Vocabulary in Another Language. Cambridge: Cambridge University Press. 
Schmitt, N. (2008). Review article Instructed second language vocabulary learning. Language Teaching Research, 12(3), 329-363.

\section{Contact}

Alastair Graham-Marr, Associate Professor

Department of Liberal Arts, Faculty of Engineering,

Tokyo University of Science

6-3-1 Niijuku, Katsushika-ku, Tokyo, 125-8585, Japan

gmarr@rs.kagu.tus.ac.jp

\section{Appendix}

\section{Questionnaire}

1. Have you previously taken a class that has used a literature circles approach?

2. Do you think literature circles is common in Japan?

3. What was your impression of literature circles? Positive or negative?

4. Could you describe some of the positive and negative aspects of the approach?

5. Was LC useful in helping you improve your vocabulary?

6. Did you feel that LC was more effective than traditional approaches in helping you develop your vocabulary?

7. Did you feel that LC was more effective than traditional approaches in helping you use newly learned vocabulary?

8. Do you prefer fiction or non-fiction?

9. Did you feel that Whodunit helped you to learn something about North American culture?

10.Do you feel that reading fiction is helpful in learning words associated with lifestyle and culture?

11.Do you feel that learning words associated with lifestyle and culture is important? 